
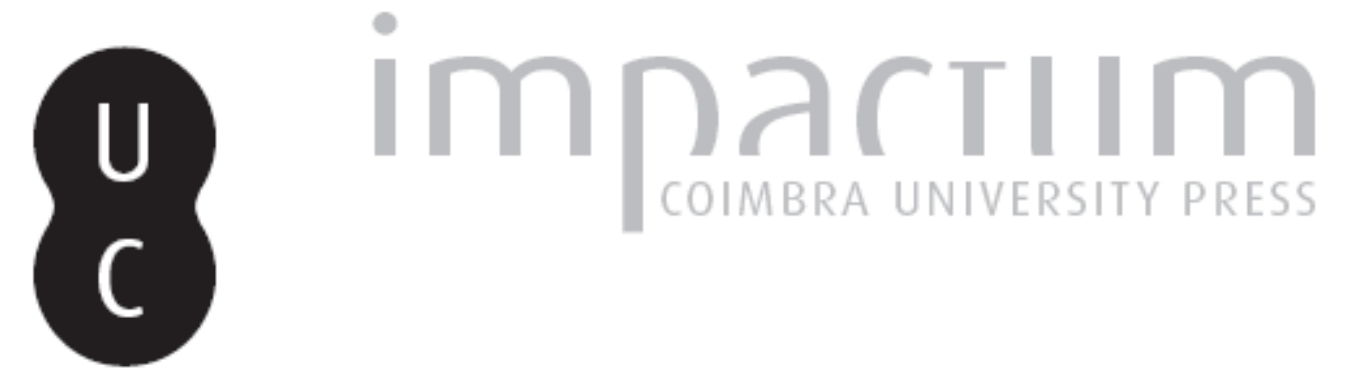

\title{
A educação cristã de crianças: algumas reflexões a partir de Kierkegaard
}

\section{Autor(es): $\quad$ Paula, Marcio Gimenes de}
Publicado por: Universidade Católica de Petrópolis; Instituto Brasileiro de Informação em Ciência e Tecnologia

URL

persistente:

URI:http://hdl.handle.net/10316.2/33079

DOI:

DOI:http://dx.doi.org/10.14195/1984-6754_2_4

Accessed : $\quad$ 26-Apr-2023 16:09:38

A navegação consulta e descarregamento dos títulos inseridos nas Bibliotecas Digitais UC Digitalis, UC Pombalina e UC Impactum, pressupõem a aceitação plena e sem reservas dos Termos e Condições de Uso destas Bibliotecas Digitais, disponíveis em https://digitalis.uc.pt/pt-pt/termos.

Conforme exposto nos referidos Termos e Condições de Uso, o descarregamento de títulos de acesso restrito requer uma licença válida de autorização devendo o utilizador aceder ao(s) documento(s) a partir de um endereço de IP da instituição detentora da supramencionada licença.

Ao utilizador é apenas permitido o descarregamento para uso pessoal, pelo que o emprego do(s) título(s) descarregado(s) para outro fim, designadamente comercial, carece de autorização do respetivo autor ou editor da obra.

Na medida em que todas as obras da UC Digitalis se encontram protegidas pelo Código do Direito de Autor e Direitos Conexos e demais legislação aplicável, toda a cópia, parcial ou total, deste documento, nos casos em que é legalmente admitida, deverá conter ou fazer-se acompanhar por este aviso.

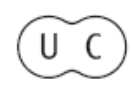



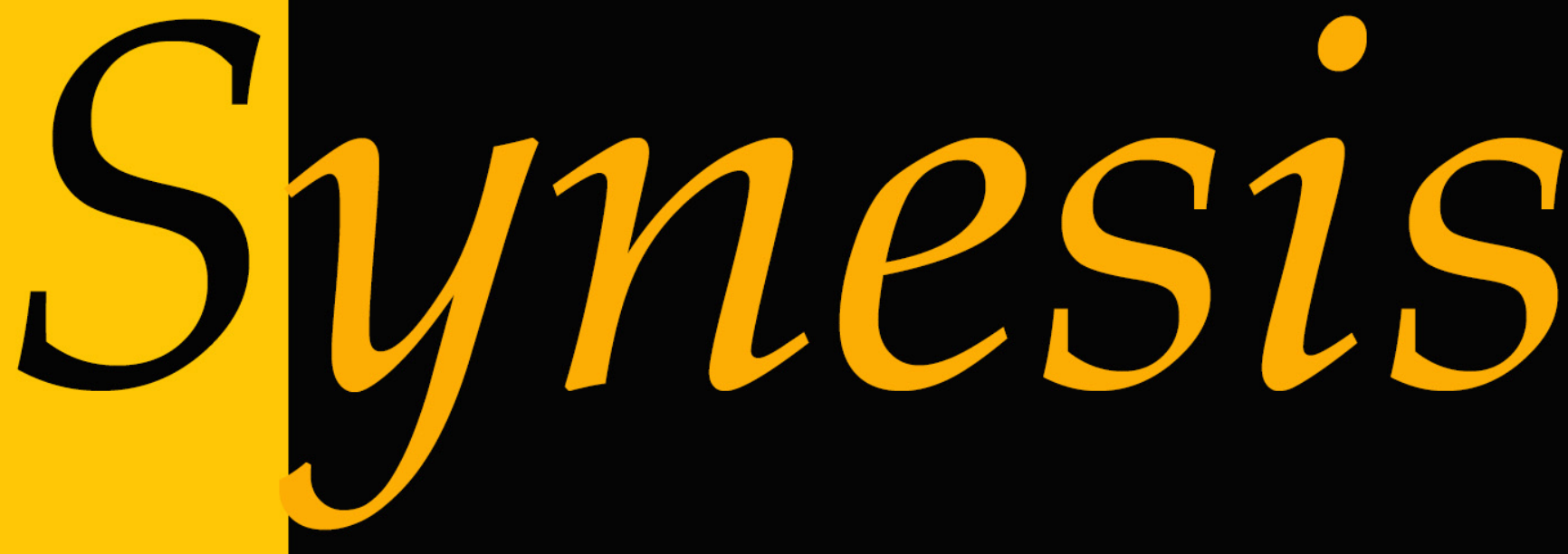

Revista do Centro de Teologia e Humanidades ISSN 1984-6754

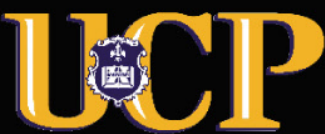




\title{
A EDUCAÇÃO CRISTÃ DE CRIANÇAS: ALGUMAS REFLEXÕES A PARTIR DE KiERKEGAARD
}

\author{
Marcio Gimenes de Paula ${ }^{1}$
}

Resumo: O pensador dinamarquês Kierkegaard (1813-1855), severo crítico da cristandade no século XIX, vê com muitas ressalvas a possibilidade de uma educação cristã de crianças. No seu entender, visto que o cristianismo é uma questão da esfera do indivíduo e da sua escolha, não se pode ensiná-lo e nem se pode colocá-lo como uma obrigação estatal. Tais teses são recorrentes em toda a sua obra, mas se tornam absolutamente explícitas tanto no Exercício do Cristianismo como na sua polêmica final contra a Igreja através dos fascículos do Instante. Desse modo, nosso intuito é avaliar tais afirmativas, o contexto onde as mesmas se inserem e sua repercussão para o pensamento filosófico e teológico da posteridade.

Palavras-chave: Cristianismo, Ética, Educação, Filosofia da Educação, Filosofia da Religião, Kierkegaard.

\begin{abstract}
The Danish thinker Kierkegaard (1813-1855), critic of Christianity in the nineteenth century, with many caveats sees the possibility of a Christian education of children. In his view, because Christianity is a matter for the individual sphere and their choice, you can not teach and you can not put it as a state obligation. These theses are recurrent throughout his work, but become quite explicit in both the Practice in Christianity and that his controversial final against the Church through the issues of The Moment. Thus, our aim is to evaluate these assertions, the context

$1 \quad$ Graduado em filosofia pela Universidade Estadual de Campinas (1999), graduado em teologia pelo Seminário Teológico Presbiteriano Independente (1994), mestrado em Filosofia pela Universidade Estadual de Campinas (2002) e doutorado em Filosofia pela Universidade Estadual de Campinas (2005). Atualmente é professor adjunto II do departamento de Filosofia da Universidade Federal de Sergipe, pesquisador da FAPITEC-SE, membro da SOBRESKI (Sociedade Brasileira de Estudos de Kierkegaard), da Sociedade Brasileira de Filosofia da Religião, do Grupo de Pesquisa Clínica Psicanalítica e cultura contemporânea da UFS, do Grupo de pesquisa sobre a obra de Kierkegaard da UNISINOS, do Grupo Crítica e Modernidade da UNICAMP e da Sociedade Feuerbach Internacional.
\end{abstract}


in which they fall and its repercussions for the philosophical and theological thought of posterity.

Key words: Christianity, Ethics, Education, Philosophy of Education, Philosophy of Religion, Kierkegaard.

INTRODUÇão: Sobre A POSSIBILIDAdE DE UMA EDUCAÇão RELIGIOSA E SUAS POSSÍvEIS CRÍTICAS

Hoje há uma constante inquietação sobre a possibilidade de ensinar o cristianismo às crianças. Para alguns, tal tarefa parece obrigatória. Para outros, parece condenável e violenta. Para outros ainda, ela parece impossível, visto que ninguém pode ensinar nada a ninguém e se tal coisa for feita ao que estamos efetivamente nos referindo? Ensinar o cristianismo aos infantes é possível? Em que bases se pode falar, portanto, em ensino religioso de crianças? Na Antiga Grécia, já se desconfiava que ninguém pode ensinar o outro a ser virtuoso, mas é isso o que almejamos quando tratamos do ensino religioso? Almejamos ensinar virtudes?

Desde os primórdios do judaísmo e, posteriormente, tanto no cristianismo como também no islamismo, a educação de crianças é um tema recorrente e aceito por estas tradições religiosas monoteístas. Os rituais judaicos (e islâmicos) da circuncisão davam a marca da inserção da criança no seio da sua comunidade de fé. No cristianismo tal marca de inserção se dá em torno da questão do batismo. Os reformadores protestantes do século XVI não alteram tal panorama e seguem a afirmar a importância do batismo infantil. É bem verdade que os mesmos, seguindo também os passos da tradição católica da crisma, optam pela confirmação ou profissão de fé dos infantes, ou seja, a criança que foi batizada sem ter consciência de tal ato precisa, quando atingir a idade adulta, escolher, de modo maduro e consciente, se deseja ou não fazer parte da comunidade de fé onde seus pais 
The apresentaram no dia do batismo. Contudo, o batismo infantil segue sendo válido e tanto no catolicismo, como no protestantismo ele tem o status de um sacramento. Será somente com um ramo mais radical da Reforma, a saber, os anabatistas que começa a se afirmar que o batismo deve ser um ato livre e consciente de cada indivíduo e não mais algo que pode ser feito pelos pais no nome de seus filhos. Desse modo, os anabatistas abolem em definitivo o batismo infantil e o mesmo só pode ser feito quando fruto de uma opção da vida adulta. Tal tese será aceita por boa parte da tradição batista e por vários ramos ligados ao pentecostalismo. $\mathrm{O}$ curioso é que tal tese também despertará dúvida em muitos teólogos católicos e reformados sobre o que significa de fato ser cristão. Em outras palavras, ela causa crises em autores clássicos católicos ou protestantes. Por isso, escolhemos aqui analisar como elas repercutem no pensamento de Kierkegaard, autor do século XIX, pertencente ao protestantismo clássico luterano.

\section{O CRISTIANISMO COMO OPÇão EXISTENCIAL EM KIERKEGAARD}

O Exercício do Cristianismo foi escrito em 1848 e publicado em 27 de Setembro de 1850. Tal obra reflete um pouco da explosiva situação social vigente na Dinamarca (e na Europa) desta época. Seu teor contém uma severa crítica aos movimentos sociais de cunho socialista que não conseguiam perceber o indivíduo. Através da comparação entre o cristianismo do Novo Testamento e a cristandade, seu autor proporciona ao leitor uma clara visão de suas severas críticas ao cristianismo no seu estágio atual. Há também acerbas críticas destinadas a Lutero e sua instituição (a Igreja Luterana), que se aliou ao poder. A cristandade acabou, no entender de Anti-Clímacus, o autor pseudonímico da obra, com o martírio e o sofrimento e, por isso, destruiu o próprio cristianismo.

O Exercício do Cristianismo é também uma resposta implícita às teses de Feuerbach sobre o cristianismo, às observações kantianas e 
hegelianas, uma crítica do positivismo de Comte e ainda uma resposta à Vida de Jesus de Strauss. Feuerbach adquire aqui o papel de aliado involuntário e adversário declarado. Ainda que o admire, Anti-Clímacus declarará o que o próprio Feuerbach certamente reconheceria: ele não quer seguir o Exercício do Cristianismo. Entender o que significa caminhar nesta escola ou aprendizado é o desafio desta obra.

A desmitologização histórico-científica nos estudos bíblicos é, no entender de Anti-Clímacus, um processo equivocado e que segue não conseguindo alcançar o cristianismo genuíno. O cristianismo é escândalo, loucura e martírio. A filosofia de Kant e de Hegel não conseguiram, de igual forma, dar tal passo.

O título Exercício do Cristianismo- é influenciado pela Imitação de Cristo de Thomas Kempis e quer dizer um treino ou iniciação no exercício do cristianismo. Trata-se de uma obra destinada ao aprofundamento e ao despertar da vida interior. Um ponto de vista cristão do que significa tornarse cristão.

Logo no início da obra, há uma parte intitulada invocação que, de modo não desproposital, assemelha-se à estrutura de uma liturgia ou ao chamamento dos fiéis para uma cerimônia religiosa. Em tal invocação, recorda-se que a passagem de Jesus Cristo pelo mundo não se tornou apenas passado histórico, mas é algo muito mais intenso. Em tal intensidade, reside o que o autor denominará de escândalo do cristianismo. Após tal invocação, há um convite para, tal como diz o Evangelho, que "venham todos os cansados e oprimidos".

Deve-se notar, entretanto, de onde procede o convite, ele é oriundo do amor. Assim sendo, é um convite destinado a todos, para que se voltem a esse amor. O convite é para todos, mas deve ser recebido por cada um, de forma individual. Aliás, o próprio convite vem na forma de um indivíduo. Nesse sentido, é que se pode entender Jesus Cristo pregando o repouso para cada pecador. Se a recepção do cristianismo se dá no interior de cada 
indivíduo, esse deve ser entendido como um sinal interior e jamais como um signo exterior.

É necessário também frisar que, do ponto de vista humano, o aviso é sempre mais importante do que aquele que avisa, isto é, é importante em si e em grau maior do que o veículo que o transmite. A vida daquele que fez o convite também não pode ser captada pela perspectiva histórica. Sua vida tornou-se o símbolo e o objeto da fé, e por seu intermédio veio o escândalo, aquilo que não se coaduna com a antiga concepção judaica da fé.

O escândalo se torna ainda mais chocante quando se descobre que aquele que convida é Jesus Cristo, um homem terreno. Muitos admiram o Jesus celestial, mas poucos reconheceriam um convite feito pelo Jesus terreno e que assume a forma do servo. Anti-Clímacus chama a atenção para o fato de que o retorno de Jesus para a glória celestial não é objeto de estudo, mas sua estadia terrena é objeto de estudo.

Note-se que as palavras de Jesus só serão verdadeiras se ele falar com os homens no seu rebaixamento e não na sua glorificação. Deve-se captar suas palavras no breve intervalo entre seu rebaixamento e ascensão. Assim sendo, nada se pode afirmar deste Cristo pela história. Ele é paradoxo, objeto da fé. Afinal, toda transmissão histórica transmite um dado saber e Cristo é o saber em si.

Pode-se, então, provar historicamente a divindade de Cristo? Ora, tal coisa seria impensável, uma vez que se tem que enfrentar a terrível contradição de querer falar sobre a divindade de um homem particular, ou seja, Jesus de Nazaré. Obviamente que o pensamento de boa parte das pessoas achará tal coisa ilógica ou escandalizadora. Tomar um homem particular por Deus é promover o escândalo e posicionar-se contrariamente à razão.

Outro erro comum ocorrido na história da Igreja é que ora se toma Jesus de modo demasiado divino, ora ele é tomado de forma demasiadamente humana. Querer usar a história para provar que Cristo era Deus é um projeto fadado ao fracasso. Antes deve-se perguntar se a continuidade da vida de 
Cristo é mais importante do que sua vida terrena. Para Anti-Clímacus, sua importância reside exatamente aí: Deus se revela na forma de um homem comum, ou seja, a ênfase deve ser feita no Deus que vem na forma de um homem.

É certo que em Sócrates, por exemplo, o significado de sua vida importa mais do que suas palavras. Já na figura de Cristo é evidente que a mensagem é de suma importância, mas esta também é inseparável do mensageiro que é o servo e, ao mesmo tempo, o salvador. Afinal, Cristo é o servo que transmite e é a própria verdade: "Jesus Cristo é objeto da fé; é necessário crer nele ou escandalizar-se; pois 'saber' significa precisamente que não se trata dele. A história pode transmitir o saber, e em larga medida, mas o saber aniquila Jesus Cristo" (KIERKEGAARD, 1982, 33).

Tal idéia do Cristo enquanto sofredor precisa ser recuperada urgentemente, visto que a cristandade a aboliu e decretou, dessa forma, o fim do escândalo. Somente o rebaixamento de Cristo é a real condição para compreender a sua mensagem. A cristandade empalideceu a mensagem de Cristo e, por isso mesmo, ele precisa ser reintroduzido nela.

Falar de Cristo como um contemporâneo também não ajuda em nada, pois não se trata de uma questão histórica. É evidente que o sistema se chocará com tal concepção e julgará que isso não passa de uma loucura subjetiva de algum indivíduo que se autonomeou Deus. Alguns até, talvez, discutam sobre se Cristo tinha o desejo de montar alguma organização política ou defender um determinado sistema de governo (tal como procede Strauss). O que se deve compreender, portanto, é que o divino e o humano são partes integrantes (e inseparáveis) da vida de Jesus.

Aquele que convida- e é o escândalo- é também Deus (e não somente homem). Dessa maneira, a questão divina de quem convida vai muito além da pura compaixão diante da miséria humana, trata-se de uma compaixão divina e por isso ele é a ocasião de escândalo.

A loucura reside no fato dele ser absoluto, pouco se importando 
com a contemporaneidade do discípulo, mas sim com o tornar-se cristão. Nessa perspectiva, o cristianismo histórico é um engano e todos os cristãos verdadeiros são contemporâneos de Cristo (independente da época em que vivem).

O que fará diferença é o indivíduo diante do seu Deus e o reconhecimento da dificuldade do processo do devir cristão. A consciência do pecado é a reabilitação de tal indivíduo. Tal consciência é a porta estreita narrada pelos Evangelhos e fundamento da fé.

Igualmente instigante é a análise que Anti-Clímacus faz daquele trecho evangélico que diz: "felizes daqueles para quem eu não sou uma ocasião de escândalo". Em outras palavras, felizes são aqueles que, apesar de tudo, seguem crendo e não se escandalizam. Aqueles cuja fé supera o escândalo. Note-se ainda que o termo escândalo é um termo cristão por excelência e ele é uma passagem obrigatória para a fé. Ele transforma uma possibilidade em ato.

O escândalo refere-se ao Deus-Homem. Com efeito, não é toda a humanidade que se transforma em Deus, mas sim um certo e específico homem, a saber, Jesus. Tal escândalo ocorre de duas formas: através da elevação de um homem que se diz Deus e através do rebaixamento de Deus ao mais baixo estágio da condição humana. Tal Homem-Deus é o paradoxo absoluto. Em seu posicionar-se aparece um novo confronto: o confronto com a ordem estabelecida que surge através da luta entre Cristo e os poderes mundanos.

O confronto com a ordem estabelecida se produz devido ao natural choque interior do Homem-Deus com essa ordem. O processo de interiorização desmascara a suposta divindade da ordem estabelecida. Nesse sentido é que se deve compreender Jesus Cristo como um escândalo, pois ele não junta o exterior (hábitos) com a piedade (interioridade). Suprimir o escândalo equivale a suprimir o próprio Cristo. É, com efeito, a possibilidade do escândalo essencial no sentido da elevação, onde um homem particular 
fala e age como se fosse Deus. Ele pretende ser Deus, isto é, no sentido do termo composto Homem-Deus.

O escândalo é um sinal de contradição e por isso não pode ser compreendido pela lógica sistemática. O sofrimento de Cristo é tão escandaloso como o fato dele beber e comer. Note-se que a possibilidade deste escândalo essencial significa rebaixamento; onde aquele que se toma por Deus se mostra como um homem de humilde condição, pobre, sofredor e, finalmente, impotente. Falando de outra forma, ele efetiva em ato o escândalo de Deus se tornar homem.

Sendo Deus um homem, surge a pergunta: Ele não é filho de um carpinteiro? Não é humano? Tais perguntas revelam a desconfiança existente nos contemporâneos de Jesus. Assim sendo, de que serve a contemporaneidade com Cristo, uma vez que existe a desconfiança? Pedro será uma figura exemplar nesse sentido, pois ele representa o escândalo e a dúvida.

A encarnação acompanha o escândalo, e ambos são seguidos do sofrimento para Cristo e seus imitadores. O fim do escândalo representa a equivalência entre paganismo e cristianismo. Tal equivalência gera uma religiosidade banal que desvirtua a dureza dos textos bíblicos. Afinal, o sofrimento e o martírio são conseqüências inevitáveis do cristianismo. A adaptação do cristianismo à ordem mundana representa o fim do escândalo.

Para melhor estudo desta questão do Homem-Deus deve-se saber, de antemão, que ela não pode ser estudada pela filosofia moderna, uma vez que essa parte da dúvida e não da admiração. Outro erro é acreditar em doutrinas prontas e julgar que o cristianismo é comunicação direta. Ora, se o próprio mestre é mais do que a doutrina, trata-se de saber que existe uma reduplicação, ou seja, um paradoxo da comunicação.

A diferença essencial entre Cristo e o homem é que Cristo é mais importante do que sua doutrina, já no homem a doutrina é mais importante do que o seu mensageiro. Portanto, Cristo é mais do que um homem. $\mathrm{O}$ Deus-Homem é um sinal e é diferente do imediato. O sinal é aquilo que 
aponta para algo, mas tal gesto só pode ser captado por quem sabe do que se trata e entende a linguagem do sinal: "Um sinal não é o que imediatamente é, pois nenhum sinal é uma determinação da reflexão. Um sinal de contradição é o que atrai sobre si a atenção e quando esta o atende, manifesta-se contendo uma contradição" (KIERKEGAARD, 1978, 300).

O Homem-Deus é, portanto, equivalente a um sinal de contradição. O milagre chama a atenção para esse sinal, notadamente para os que não crêem. Todavia, não se trata de uma comunicação direta. A sobrevivência da doutrina e o esquecimento de Cristo representam o fim do cristianismo. A forma do servo é a do incógnito, isto é, aquele que não se dá a conhecer. Na perspectiva divina, trata-se de um homem particular. Logo, mesmo se for contemporâneo de Cristo, devido ao seu rebaixamento, não seria possível reconhecê-lo. Note-se que esse reconhecer a Deus seria uma blasfêmia ou pecado contra o Espírito Santo, aquele para o qual não há perdão, pois se existe incógnito, não há comunicação direta e isso ocorre por causa de uma estratégia divina.

Diante da impossibilidade da comunicação direta, resta a comunicação indireta. Ocorre, então, uma reduplicação da comunicação. Em tal reduplicação, dissolve-se a personalidade de quem comunica e não se caminha para a objetividade pura, mas há uma espécie de pseudonímia nesta dupla reflexão. Em outros termos, ocorre algo que se pode caracterizar como uma espécie de nó dialético e uma comunicação com crise de esquizofrenia, por causa das suas muitas personalidades.

Há também em tal tipo de comunicação um discurso da opção, isto é, o ser humano pode decidir no que deseja crer ou não. Tal estratégia de comunicação indireta não é entendida nem pela filosofia especulativa e nem pela cristandade. Todavia, essa comunicação revela a seriedade do milagre de Cristo e do discurso da opção. Para Anti-Clímacus, somente um ídolo é reconhecido diretamente. Cristo é o eleito de Deus mas é, ao mesmo tempo, o seu rejeitado. 
A incognoscibilidade de Deus é decorrência do seu amor pelo homem. Tal coisa tem que ser assim, pois não há homem capaz de compreender um Deus sofredor na pessoa de Cristo. A possibilidade do escândalo é a negação da comunicação direta e marca também o abismo que há entre Deus e os homens. Já a comunicação direta é a recusa de tal diferença, representando também o fim do escândalo. Note-se que a comunicação indireta pode tanto seduzir quanto criar repulsa em quem a ouve.

Todavia, só se pode negar a comunicação direta através da fé. Tal tipo de comunicação não se importa com o tornar-se cristão e, por isso mesmo, só aparenta seriedade. De igual modo procede a filosofia moderna, crendo na comunicação direta e vendo a fé como imediata. Tal filosofia é mera opinião doutrinária, representando o fim do escândalo e do paradoxo.

O Deus-Homem só pode ser entendido como objeto da fé justamente por ser também uma possibilidade de escândalo. Não é possível entender o Deus-Homem dissociando-o do escândalo. Somente assim é que se pode se aproximar do seu amor e da fé. Reconhecer um deus diretamente equivale a paganismo, e a filosofia especulativa comete esse erro ao racionalizar a fé. Por isso, para Anti-Clímacus, dezoito séculos de cristianismo nada podem provar, exceto para a especulação.

Um cristão deve se esquecer de todo o mundo a fim de lembrarse de uma única coisa: Jesus Cristo. Ele é atraído para Cristo não apenas por mera sedução, mas o rebaixar-se desse Deus é, para ele, uma verdadeira ascensão. Crer no Deus que se rebaixa é a condição cristã para ascender com ele. Cristo, ao se fazer o menor de todos os homens, dá igual condição para todos os que querem segui-lo.

Tal Cristo é filho de Deus, aquele que é eternamente. Sua história de sofrimento é real e os homens são seus contemporâneos quando reconhecem tal sofrimento. Dessa forma, os cristãos também tem o dever de amar, de modo inclusivo, a todos os homens. Cristo é a opção de sofrimento de Deus pelos homens. Tal sofrimento é inevitável e ocorre por amor. 
A missão desse Cristo é congregar todos os que se dispõe a segui-lo e a seguir sua cruz. Não recusar o sofrimento é dever do imitador de Cristo. Somente desse modo é que se testemunha a fé. Também é importante notar que o homem, apesar de tudo, segue fazendo imagens desse Deus (como já notaram Calvino e Feuerbach). O que é importante destacar, no entanto, é que, para ele (o cristão autêntico), seu Deus é mais do todas elas. Desse modo, se ele tiver em mente o real rebaixamento de Cristo, deve igualmente se rebaixar.

Em que sentido, então, se afirma que Cristo foi a verdade? Afinal, enquanto indivíduo e Deus, ele se recusou a responder a pergunta de Pilatos acerca da verdade (Jo 18:38) e silenciou. Certamente ele não é uma verdade triunfante como a Igreja Triunfante, mas uma verdade a ser testemunhada e seguida com martírio, como a Igreja Militante. Dessa maneira, o principal desafio do genuíno cristianismo é mudar e reintroduzir seus conceitos na cristandade. Para tanto, um cristão não deve ser apenas um admirador (tipo estético), mas um imitador de Cristo (sentido religioso). Rebaixar-se é, portanto, elevar-se. Elevar a fé e o cristianismo.

\section{Conclusão: KierkegaARd COMO CRÍTICO DA EDUCAÇão CRISTÃ de CRIANÇAS}

Para Kierkegaard, o cristianismo pervertido do seu tempo transforma o batismo em mero ato social. Aliás, era isso o que ocorria em toda a Dinamarca. Para ele, há uma grande incoerência em ser pai e mãe numa religião- como o cristianismo- que preconiza o celibato. Igualmente risível seria o caso do comerciante, que quer levar vantagem em tudo no seu comércio, mas filia-se ao cristianismo, onde tudo deve ser abandonado. $\mathrm{O}$ próprio auto-sacrifício da Eucaristia é ocultado na vida de tal pessoa. Outra cena deplorável: o estudante de teologia, que fala dos valores do Reino de Deus, mas busca primeiramente seu salário como pastor da cristandade.

$\mathrm{O}$ autor dinamarquês, muito influenciado aqui, na fase final de 
sua produção por Schopenhauer, é severo crítico do batismo infantil e do casamento. Eles seriam modalidades de um cristianismo para os outros. Casamento e batismo seriam superações do ético, mas ainda não teriam alcançado um estádio religioso. A educação infantil das crianças no protestantismo é, nesse sentido, uma mentira, pois ela repousa num egoísmo dos pais e em algo supostamente natural. $O$ homem não é naturalmente religioso, mas precisa fazer esforço para chegar a isso. Note-se aqui a verve irônica de Kierkegaard e sua retórica do exagero:

A verdade é que não se pode tornar cristão como criança. A coisa é tão impossível como o é para uma criança engendrar crianças. Tornar-se cristão supõe, segundo o Novo Testamento, um crescimento humano acabado, a maturidade, a virilidade no sentido natural, para tornar-se cristão rompendo com todas as coisas às quais se está ligado imediatamente. Tornar-se cristão supõe, segundo o Novo Testamento, a consciência pessoal do pecado e a consciência de ser um pecador. Vêse desde logo que toda esta história da criança tornando-se cristã e devendo tornar-se a esta idade não é nem mais nem menos do que uma bagatela que os pastores, que falam bonito de bagatelas, sem dúvida em virtude de seu juramento ao Novo Testamento, inculcam nas pessoas para justificar seu trabalho e sua carreira (KIERKEGAARD, 1978: 340).

Com efeito, a educação cristã de crianças só pode ser compreendida sob a ótica de que o próprio cristianismo não pode ser comunicado 
diretamente, mas por uma comunicação indireta. Tal processo também só pode ser compreendido se o discípulo se mostra preparado para o processo, o que implica numa escolha de sua parte. Não pode haver cristianismo, e nem educação cristã, com imposição dos pais, da Igreja ou do Estado. Kierkegaard só poderia concluir dizendo que ninguém nasce cristão, mas torna-se.

\section{Referências Bibliográficas}

KIERKEGAARD, S.A. L'École du Christianisme- vol. 17/ Oeuvres Complètes de S.Kierkegaard, tradução de P.H. TISSEAU e Else-Marie

JACQUET-TISSEAU, 1ª edição, Éditions de L'Orante, Paris, 1982.

KIERKEGAARD, S.A. El Instante. Editorial Trotta, Madrid, 2005.

KIERKEGAARD, S.A. Textos Selecionados. Editora UFPR, Curtiba, 1978. 